\title{
Trajetórias Terapêuticas Familiares: doenças raras hereditárias como sofrimento de longa duração
}

\author{
Family Therapeutic Trajectories: \\ rare hereditary diseases involving long-term suffering
}

Waleska de Araújo Aureliano ${ }^{1}$

${ }^{1}$ Instituto de Ciências Sociais Universidade do Estado do Rio de Janeiro. R. São Francisco Xavier 524/2。, Maracanã. 20550-900 Rio de Janeiro RJ Brasil. waurelianorio@gmail.com
Abstract This article analyzes common elements in the trajectory of people affected by rare hereditary diseases in Brazil, focusing on the search for diagnosis and treatment, and the reproducibility in the family. Rare diseases affect 65 people in every 100 thousand. These are usually chronic and degenerative conditions, many incurable or without effective treatment. About $80 \%$ of rare diseases are genetic in origin and can be inherited. This fact has important implications for family health care policies, reproduction, and care for clinical conditions that, in some cases, spanned generations. To analyze the data, two theoretical axes are articulated: family and kinship studies, and analyzes of long-term suffering. The research investigated people affected by rare hereditary diseases and their families, in the political scenarios in which these actors circulate, such as patient associations, scientific congresses and public hearings. There is evidence of the need to build a continuous agenda on rare diseases in Brazil capable of effectively promoting universal and integral access of the affected persons to the public health system, and seeking for solutions to alleviate suffering that threatens the very continuity of the family.

Key words Rare disease, Family, Kinship, Genetics.

Resumo Este artigo analisa elementos comuns na trajetória de pessoas afetadas por doenças raras hereditárias no Brasil, tendo por cerne a busca por diagnóstico e tratamento, e a reprodutibilidade da familia. Classificam-se como "raras" as doenças que afetam 65 pessoas a cada 100 mil. São condições geralmente crônicas e degenerativas, muitas delas sem cura ou tratamento efetivo. Cerca de $80 \%$ das doenças raras têm origem genética e são hereditárias. Este dado traz implicações importantes no que diz respeito às políticas de atenção à saúde da família, à reprodução e ao cuidado para condições clínicas que, em alguns casos, atravessam várias gerações. Para análise dos dados, articulam-se dois eixos teóricos: os estudos de família e parentesco e as análises sobre os sofrimentos de longa duração. A pesquisa desenvolveu-se junto a pessoas afetadas por doenças raras hereditárias e seus familiares, nos cenários políticos nos quais esses atores transitam, como associações de pacientes, congressos científicos e audiências públicas. Evidencia-se a necessidade de construção de uma pauta contínua sobre as doenças raras no Brasil, capaz de promover de fato o acesso universal e integral das pessoas afetadas ao sistema público de saúde, e buscar soluções para minorar sofrimentos que ameaçam a própria continuidade da família. Palavras-chave Doença rara, Família, Parentesco, Genética 


\section{Introdução}

Segundo definição do Ministério da Saúde, classificam-se como "raras" doenças que afetam 65 pessoas a cada 100 mil ou 1,3 pessoa a cada duas mil'1 São condições geralmente crônicas e degenerativas, com alto grau de morbimortalidade, muitas delas sem cura ou tratamento efetivo. Apesar de não haver consenso quanto ao número exato, estima-se que existem entre seis e oito mil doenças raras, $80 \%$ delas são de origem genética, sendo em muitos casos hereditárias. Elas afetam cerca de $8 \%$ da população mundial e, no Brasil, estima-se que há entre 13 e 15 milhões de pessoas com alguma doença rara. Por serem condições incomuns, o correto diagnóstico leva, na maioria dos casos, muito tempo para ser concluído ${ }^{2,3}$. Além disso, não existe tratamento efetivo para o controle de grande parte das doenças raras atualmente identificadas. Estima-se que apenas 10\% delas possuem algum tratamento medicamentoso específico que, em um número considerável de casos, são medicações de alto custo ${ }^{4}$.

Em janeiro de 2014 foi publicada a portaria 199, que define a Política Nacional de Atenção Integral às Pessoas com Doenças Raras (PNAIPDR $)^{1}$. Um grupo de trabalho foi criado no Ministério da Saúde, em 2012, para redigir essa política e dele participaram agentes do governo, pesquisadores, médicos e associações de pacientes. A PNAIPDR prevê a habilitação de serviços de referência, com o objetivo de oferecer diagnósticos mais precisos e rápidos, possibilitando o início de tratamentos mais eficazes para oferecer melhor qualidade de vida aos doentes. Para isso, ações e procedimentos deverão ser criados no Sistema Único de Saúde (SUS), entre elas a ampliação da lista de medicamentos oferecidos, exames de DNA e aconselhamento genético. Até março de 2017, o Ministério da Saúde habilitou sete estabelecimentos de saúde como serviço de referência em doenças raras.

Para este artigo, analiso elementos comuns na trajetória de pessoas afetadas por doenças raras hereditárias no Brasil, tendo por cerne a busca por diagnóstico e tratamento, e a reprodutibilidade da família. A escolha por delimitar a abordagem às doenças raras hereditárias deve-se ao fato de que boa parte dessas condições carrega em si um componente genético que pode ser transmitido ou herdado (embora nem toda doença genética seja hereditária). Esse dado traz implicações importantes no que diz respeito às políticas de atenção à saúde da família, a reprodução e o cuidado para condições clínicas que, em alguns casos, atravessam várias gerações.
Nesses casos, não se trata apenas do cuidado dirigido a um sujeito específico, mas à família como um todo, em seus projetos de reprodução e existência, que podem ser afetados. Diante de uma doença rara hereditária várias pessoas serão incluídas em um diagnóstico, como irmãos, primos, sobrinhos, por exemplo. Por outro lado, a duração e os efeitos de uma doença rara podem implicar necessidades de cuidado extenuantes que afetam significativamente outros membros da família, notadamente as mulheres. Diferente de um diagnóstico de hipertensão ou diabetes, o diagnóstico de doença rara hereditária é algo que atravessa vários corpos, tanto pelo componente genético que foi (ou pode ser) transmitido ou herdado, e que não é passível de ser controlado ou alterado por ações do sujeito (dieta, exercícios), quanto pelas condições físicas debilitantes que vão exigir cuidados de outrem até o fim da vida do paciente.

$\mathrm{O}$ artigo está divido em duas partes. Na primeira apresento brevemente o escopo teórico privilegiado para a análise, qual seja, os estudos antropológicos sobre família e parentesco, e sobre os sofrimentos de longa duração. $\mathrm{Na}$ segunda parte, analiso os dados coletados no trabalho de campo articulando três pontos que fazem parte da vivência de uma doença rara hereditária: a) a busca pelo diagnóstico, b) o acesso aos tratamentos (ou a falta deles), e c) as questões concernentes à reprodução e continuidade da família. Por fim, as considerações finais apontam para necessidade de uma pauta contínua sobre as doenças raras, a fim de permitir o acesso universal das pessoas afetadas ao sistema de saúde e uma melhor compreensão dos aspectos simbólicos, afetivos e relacionais que fazem parte da vida de pessoas que enfrentam sofrimento de longa duração.

\section{Metodologia}

Os dados analisados são fruto de pesquisa qualitativa, conduzida desde 2013, em diferentes cenários: internet, associação de pacientes, congressos científicos, hospitais e audiências públicas (estadual/federal). Ao buscar materiais para análise nesses locais a intenção foi abarcar o percurso público realizado por pessoas com doenças raras, entendendo que esse é um grupo heterogêneo, marcado por alguns elementos comuns e outros particulares, relacionados não apenas à doença em si, mas também às condições materiais de existência dos sujeitos. As pessoas que estão nos consultórios médicos ou nas redes sociais nem 
sempre tomam parte nos eventos científicos ou políticos sobre doenças raras, nem estão articuladas com a indústria farmacêutica ou o Estado. Neste sentido, faz-se necessário o cruzamento desses diferentes cenários para se poder alcançar uma melhor compreensão de como a doença rara hereditária é percebida e vivenciada por pessoas oriundas de diferentes extratos sociais, com acessos distintos ao sistema de saúde e com particularidades que dizem respeito a valores relacionados ao corpo, à família e à saúde.

O trabalho de campo deu-se basicamente através da participação em eventos públicos abertos. Foram observados dois congressos sobre doenças raras, realizados em Brasília (2013, 2016), dos quais fizeram parte associações de pacientes, indústria farmacêutica, representantes do Ministério da Saúde e pesquisadores acadêmicos. Ainda em Brasília, acompanhei uma audiência pública realizada na Comissão de Seguridade Social e Família da Câmara dos Deputados, em 2013, e em 2016 participei do VIII Fórum Nacional de Políticas de Saúde, que teve como temática as doenças raras. Este evento foi realizado no Senado Federal por uma organização civil e contou com a presença de agentes do governo federal, indústria farmacêutica, médicos, pesquisadores e pacientes. No Rio de Janeiro, foram observados dois eventos sobre doenças raras realizados na Assembleia Legislativa do Estado, ambos em 2014.

Além da participação nesses eventos, acompanhei as atividades de uma associação de pacientes afetados por uma doença rara que tem formas adquiridas e hereditárias, as ataxias. Realizei entrevistas semiestruturadas com membros de duas famílias que faziam parte dessa associação e que tinham uma das formas hereditárias de ataxia, a Doença de Machado-Joseph. Entrevistei pessoas diagnosticadas com a doença e alguns de seus familiares sem sintomas, mas com risco de serem portadores da condição genética que causa a enfermidade. A DMJ é a forma de ataxia hereditária mais comum no Brasil, tem expressão tardia e é autossômica dominante ${ }^{5,6}$. Entre os sintomas estão a desarticulação da fala, desequilíbrio da marcha, paralisia de membros inferiores e superiores e dificuldades para deglutição. Os sujeitos afetados podem viver muitos anos com a doença em evolução. Por fim, durante três meses observei as consultas realizadas no ambulatório de genética médica de um hospital universitário do Rio de Janeiro.

Os dados foram trabalhados à luz de dois eixos de análise. Por um lado, os recentes estudos sobre família e parentesco, na sua relação com as biotecnologias, que têm renovado esse campo tradicional da pesquisa antropológica ${ }^{7-9}$. Além disso, a análise se ancora também nos estudos dos sofrimentos de longa duração que vão considerar as complexas interações entre o sujeitosociedade-cultura na experiência da doença e o papel central das narrativas como forma de alcançar as práticas e representações que emergem nos processos de adoecimento crônico ${ }^{10-13}$.

A pesquisa foi submetida e aprovada por comitê de ética em pesquisa com seres humanos.

\section{Família e sofrimentos de longa duração}

Presentes historicamente na antropologia como importante linha teórica, os estudos de família e parentesco recuaram a partir dos anos 1970. Posicionamentos críticos no interior da disciplina sugeriram que os termos analíticos utilizados para definir família e parentesco refletiam os valores da sociedade dos pesquisadores, nas quais essas categorias são significadas, principalmente, através de uma noção biológica do vínculo, centrada na consanguinidade ${ }^{14}$.

A partir dos anos 1990 ocorre uma retomada do tema na antropologia fomentada pelos estudos das sociedades complexas e em relação com as áreas da saúde, das novas tecnologias reprodutivas e dos estudos feministas ${ }^{15}$. Neste cenário, muitas pesquisas se detiveram sobre as biotecnologias utilizadas nas escolhas reprodutivas contemporâneas, que estão informadas por novos arranjos familiares presentes nas sociedades modernas e balizados por diferentes questões: da reivindicação de autonomia das mulheres para o exercício de uma "maternidade independente"16 à judicialização da paternidade com os testes de DNA $^{17}$; da construção de famílias homoafetivas à transformação do "problema em ter filhos" em "problema médico", capaz de ser solucionado com a tecnologia biomédica 9 .

Família e parentesco ressurgem como categorias marcadas fortemente pelo direito e pela medicina, ambos interconectados nos processos de definição e construção desses conceitos e informados pelas novas biotecnologias. Por um lado, essas tecnologias colocaram em questão a dimensão biológica da definição de parentesco ao apontar para formas de reprodução nas quais seria possível haver uma "confusão" dos lugares tradicionalmente ocupados por pais, mães e filhos na nossa sociedade. Por outro, elas estariam contribuindo para definições medicalizadas de família e parentesco, especialmente através da genética e de pesquisas sobre doenças crônico-degenerativas, nas quais se percebe a construção de identidades clínicas e normas reprodutivas pau- 
tadas na ideia do "patrimônio genético" herdado da família ${ }^{18}$.

Nesse processo, novas formas de organização política e representações sociais emergiram para tratar de questões relacionadas aos processos de saúde e doença, a constituição dos vínculos familiares e de parentesco, e a produção de identidades clínicas antes associadas ao "sangue", e agora marcadas pela ideia do "patrimônio genético". Rabinow $^{19}$ definiu o termo biossociabilidade para enfatizar a formação de novas identidades e práticas individuais e coletivas no âmbito do capitalismo moderno, que seriam marcadas pela ênfase na dimensão biológica, reforçada a partir do Projeto Genoma Humano.

No entanto, essas biotecnologias passam por questionamentos quanto a sua real utilização para pessoas que são assintomáticas e que podem, a partir da testagem preditiva, por exemplo, serem confrontadas com uma situação de grande ansiedade frente ao diagnóstico do provável desenvolvimento de uma doença crônica. Testes genéticos para o câncer de mama hereditário, por exemplo, podem criar graus de ansiedade difíceis de serem resolvidos. No caso de resultados positivos que aumentam o risco para este tipo de câncer, a solução apresentada passa muitas vezes pela retirada preventiva das mamas, uma decisão complexa e nem sempre acessível para todas as mulheres ${ }^{20,21}$.

Além disso, a disseminação desses testes poderia vir a formar uma nova classe de pessoas estigmatizadas: os doentes pré-sintomáticos, pessoas que são completamente saudáveis, mas cujos testes genéticos apontam para possibilidade de desenvolverem uma doença no futuro. A devolução e interpretação dos resultados também pode despertar sentimentos de rotulação, ansiedade e invasão de privacidade entre pessoas que não possuem qualquer doença ${ }^{22}$, mas carregam um gene "fora do padrão", e ainda levar a situações de "discriminação genética", especialmente no mundo do trabalho, como demonstrado por Guedes e Diniz ${ }^{23}$.

É neste sentido que alguns pesquisadores chamam a atenção para os impactos emocionais, subjetivos e sociais envolvidos na disseminação dos testes genéticos, alertando para necessidade de atitudes eticamente responsáveis por parte dos profissionais de saúde, especialmente aqueles encarregados de realizar o aconselhamento genético $(\mathrm{AG})^{24-27}$. Observa-se que nem sempre os testes e as informações oferecidas no AG promovem o empoderamento dos sujeitos frente às adversidades em saúde que possam vir a enfrentar em decorrência de uma condição genética. Antes, tais informações podem gerar conflitos difíceis de serem desfeitos considerando-se o limitado leque de opções terapêuticas (quando elas existem) ou ações possíveis que as pessoas afetadas podem realizar. Novoas e Fróes Burnham ${ }^{26}$, por exemplo, chamam a atenção para distinção que seria necessária, segundo elas, entre os exames genéticos que realmente podem contribuir para a melhora do paciente e aqueles que apenas apontam a origem de problemas, para os quais ainda não há solução. Já Corrêa e Guilam ${ }^{27}$ nos mostram como o AG pré-natal pode se tornar fonte de angustia e ansiedade num contexto como o nosso, onde o aborto em casos de malformação fetal não é legalizado, contradizendo a expectativa de autonomia da mulher e poder de escolha evocada pelo AG. Essas são situações que nos mostram o caráter ambivalente de tais tecnologias e seus usos, que não podem escapar a uma análise dos contextos culturais, econômicos e sociais onde elas são aplicadas.

Sendo as doenças raras em sua maioria condições crônicas degenerativas, sem perspectiva de cura, podemos pensá-las dentro da definição dos sofrimentos de longa duração. São enfermidades com grande potencial de alteração na vida dos sujeitos, tanto em função das limitações biológicas que acarretam quanto das incertezas geradas sobre seu prognóstico. Ao lado de uma grande esperança com relação ao futuro da pesquisa genética temos uma enorme ausência de terapias efetivas para essas enfermidades. Ao contrário de outras doenças de longa duração, como o diabetes ou a hipertensão, muitas doenças raras não têm sequer a perspectiva do controle dos sintomas. A convivência com uma enfermidade degenerativa como as ataxias ou as distrofias, por exemplo, demandará ajustes constantes na vida das pessoas diante das transformações sucessivas e ininterruptas pelas quais seus corpos passarão.

Nos casos em que a manifestação da doença se dá no início da vida, o esforço da família com os cuidados infantis será acrescido de uma série de novas ações, além das já demandadas para essa fase, e que se estenderão por toda a vida dos sujeitos afetados. Para as doenças de expressão tardia, o desafio está em administrar a ruptura causada pela doença em corpos antes saudáveis, a gestão desse corpo no mundo do trabalho e na família, e a convivência, quase sempre, com a ausência ou com os altos custos dos tratamentos. Em ambos os casos, a doença rara hereditária acaba por afetar e envolver toda a família de diversas formas: o cuidado imediato do familiar afetado, a reorganização do espaço físico da casa, a preocupação 
com a própria saúde e a da prole, se ela já existir, e de demais parentes consanguíneos.

Desta forma, as doenças raras hereditárias podem ser consideradas sofrimentos de longa duração que atravessam gerações, pois elas não se encerram em corpos individuais, localizados no tempo e no espaço. Ao contrário, a busca pelo “problema da família” exige muitas vezes um retorno ao passado familiar na tentativa de identificação da origem da doença, assim como se projeta para o futuro, sobre as gerações que ainda virão. Contudo, a ideia da herança genética e seus impactos sobre a reprodução da família não tomam proporções iguais em todos os casos, como mostram alguns estudos ${ }^{28-30}$. Lógicas distintas permeiam as percepções de risco e responsabilidade. O que talvez podemos apontar como elemento comum é a valorização da família como núcleo do cuidado, e seu papel central no campo político e social na busca por direitos em saúde que atendam as especificidades das pessoas com doenças raras ${ }^{31-33}$. Isso não difere muito de outras condições crônicas de adoecimento que têm na família o suporte para o cuidado, como evidenciado em algumas pesquisas ${ }^{34-36}$. O que talvez seja peculiar na doença genética rara é a perspectiva de expansão desse cuidado para várias gerações e a incerteza quanto aos possíveis suportes terapêuticos efetivos para o controle e a manutenção da vida, com e para além da doença.

\section{Discussão}

Para discussão dos dados coletados privilegiei três aspectos que estão interconectados e que aparecem de forma recorrente nas narrativas de pessoas com doenças raras hereditárias: a) a busca pelo diagnóstico, b) o acesso aos tratamentos, e c) as questões concernentes à reprodução e continuidade da família. Esses três pontos compõem um núcleo agregador da experiência dos sujeitos, apesar das particularidades que dizem respeito às diversas doenças raras identificadas na literatura médica.

Uma das principais queixas de pacientes refere-se ao longo tempo que levaram até chegar a um diagnóstico preciso. Nas famílias afetadas pela DMJ, os sintomas eram quase sempre evidentes em alguns parentes, porém nem sempre se tinha um nome para a doença e, menos ainda, o conhecimento sobre a sua causa:

A gente soube porque nossa avó, eu lembro dela, eu bem pequenininha aqui no Rio, e ela sem andar, e era dessa doença [...] isso deve ter uns 58 anos por aí, mas eu lembro bem dela aqui sem poder andar, com uma doença que ninguém sabia o que era (S1-mulher, sem sintomas, familiares com DMJ).

Naquele tempo ainda não se sabia da doença, meu pai se tratava com doutor fulano aqui no Rio, e ele falava 'você tem uma doença degenerativa que não tem cura', mas não falava o nome e meu pai não se conformava com isso, que ele não sabia o que era e não se conformava (S2-homem, com diagnóstico para DMJ).

As duas famílias investigadas relataram que muitos de seus parentes com a DMJ receberam diagnóstico equivocado de reumatismo, labirinte e/ou depressão. Alguns deles realizaram tratamento para essas condições na esperança de melhoria dos sintomas, sem sucesso. $\mathrm{O}$ diagnóstico chega para essas famílias após um de seus membros ter contato, aleatoriamente, com algum especialista que vai solicitar um exame genético:

Quem veio descobrir foi $X$ [irmã] que mandou fazer um DNA. Ela trabalhava com um pesquisador muito inteligente, que orientou a fazer. E aí ela mandou fazer até nos Estados Unidos porque na época que ela mandou fazer por aqui não era comum, não fazia não, ela pagou um dinheirão e mandou fazer lá. Aí veio com esse diagnóstico que era Machado-Joseph (S1).

Minha prima casou com um alemão e foi morar na Alemanha, e ela se internou lá num hospital, ficou 15 dias internada, fez todos os exames e saiu de lá com o diagnóstico da doença, Machado-Joseph, ataxia cerebelar 3. Inclusive ela mandou esse diagnóstico para todas as pessoas da família porque o médico lá disse que quem tivesse essa doença na família teria ataxia cerebelar 3, quem manifestasse sintoma (S2).

A descoberta do componente hereditário não foi uma novidade em si, pois a presença de sintomas da doença em muitos parentes evidenciava que havia "um problema na família". O que o diagnóstico ofereceu foi um nome para essa condição, uma explicação para sua causa e a possibilidade de direcionamento do cuidado, além de justificar as falhas no ambiente de trabalho e possibilitar a antecipação da aposentadoria:

Eu tinha dificuldade de ficar em pé, parado, imóvel, sem se mexer, e as pessoas [no trabalho] pensavam que eu estava de brincadeira, e eu não falava pra ninguém. Enquanto o médico não me deu o diagnóstico, eu não falei pra ninguém, mas quando o médico me deu diagnóstico, aí foi tchau e benção [pediu aposentadoria] (S2).

Para eles [filhos], se vier a ter [a doença], o caminho é mais fácil, já tem um diagnóstico, porque imagine você não saber o que você tem? Hoje 
não, se acontecer já tem um caminho a percorrer (S3-mulher, com diagnóstico para DMJ).

No caso das doenças de herança autossômica recessiva que surgem na primeira infância, a busca por um diagnóstico precoce é uma das principais demandas dos pais e especialistas, sobretudo, para doenças que podem ser diagnosticadas pelos sistemas de testagem neonatal já existentes, como a fibrose cística (FC) e a fenilcetonúria (PKU), e que possuem tratamento. As doenças não testadas nos programas de triagem neonatal enfrentam outros problemas. A primeira, é a dificuldade em conseguir consulta com um especialista que irá solicitar o teste genético para definir, por exemplo, qual o tipo de uma doença que possui diferentes variações, como é o caso das mucopolissacaridoses (MPS). Nestes casos, o acesso ao medicamento pela via judicial depende do diagnóstico genético que pode demorar meses ou anos para ser conseguido:

Essa, por exemplo, que está com suspeita de mucopolissacaridose (MPS), que apareceu essa semana, a médica não estava conseguindo marcar geneticista, encaminhar para um geneticista. E demora só para marcar, para se encaminhar para um geneticista. Demora às vezes um ano e, quando vai para a genética, ainda tem que fazer toda aquela bateria de exames, para poder saber se é a doença ou não. Aí quer dizer, mais um ano, são dois anos para conseguir [diagnosticar] (S7, mãe de criança com MPS, membro de associação).

Eu lembro que a gente ia em reunião com o Estado para discutir a inclusão do teste do pezinho [na triagem neonatal do Rio de Janeiro]. A gente falava assim: 'o que adianta vocês não quererem diagnosticar? A criança vai chegar em algum momento, grave precisando de uma UTI ou grave precisando de dez medicamentos quando na realidade poderia está precisando de um só' [...] a resposta era 'do que adianta ter o diagnóstico, saber que tem fibrose cística se depois não vai ter para onde encaminhar para fazer o tratamento?' Era assim, as respostas eram desse nível. (S6, mãe de criança com FC, membro de associação).

A inclusão de testes genéticos em políticas nacionais de saúde ainda depende de uma forte atuação das associações de pacientes nos mecanismos do Estado, pois não estão implementados de forma sistemática no sistema público de saúde. Muitas famílias conseguem um diagnóstico ao participarem de pesquisas acadêmicas, através de redes de colaboração que se formam entre pacientes, pesquisadores e médicos:

Nós conseguimos os testes através da rede, é uma troca. Eles [pesquisadores] precisam do ma- terial de pesquisa, e nós precisamos dar assistência para pacientes que estão há anos buscando esse diagnóstico [de ataxia]. Mas se a verba para pesquisa acabar, os testes também acabam. Não é o SUS que dá o teste (S4-mulher, geneticista).

A pessoa não acha onde fazer o teste do suor, que é o teste realmente que vai fechar o diagnóstico [para FC], e não são poucos os casos que nem o teste do suor é conclusivo porque tem valores limiares, a pessoa vai ter que recorrer a um teste genético, aí mesmo que é muito difícil mesmo encontrar! Tem alguns lugares que fazem como parte de uma pesquisa, de um pesquisador ali da genética, trabalho do doutorado dele, não é uma coisa sistemática, não é um serviço, a pessoa faz como parte de um estudo (S8, pai de criança com FC, membro de associação).

Desta forma, percebe-se que o diagnóstico é um dos gargalos para a questão das doenças raras. Identificar corretamente a doença pode não impedir seu curso natural, especialmente no caso de doenças de expressão tardia, degenerativas e sem tratamento específico. Porém, para quem convive com uma enfermidade que está presente há décadas em suas famílias, ter um nome para ela significa preencher lacunas na compreensão dessa herança, dotando de novas compreensões o passado familiar, assim como acena com a possibilidade de estabelecer ações no presente e projetar o futuro. Por exemplo, ter o diagnóstico é o que possibilita para muitas pessoas justificar o pedido de auxílios sociais já estabelecidos para as pessoas com deficiência, mas que podem ser mais difíceis de acessar quando sobre aquela pessoa paira uma interrogação sobre sua condição de saúde, especialmente se ela tem graus variados de evolução. O relato abaixo exemplifica essa complexidade que muitas vezes obriga a pessoa com uma doença rara degenerativa a ter que provar sua condição de outras formas, se ela não possui o diagnóstico genético em mãos:

Eu já estou aqui andando de muleta, mas o médico [do INSS] diz que eu tenho bom equilíbrio, mas eu sei que vai piorar, eu me sinto cansada. Aío que eu faço? No dia da perícia eu acordo mais cedo e dou umas dez voltas na pracinha que tem perto da minha casa, porque caminhar cansa minha musculatura e o equilíbrio fica pior. E vai ser assim até eu ter o exame genético, faz quase um ano que eu fiz e não saiu ainda o resultado (S9-mulher, com sintomas de DMJ).

No caso das doenças raras hereditárias com algum tratamento específico, que será mais eficaz se iniciado precocemente, o diagnóstico correto irá determinar a qualidade de vida que a pessoa 
afetada terá e até mesmo o controle da doença em alguns poucos casos. Esse tratamento nem sempre significa o uso de medicamentos de alto custo, podendo se limitar a alterações na dieta e/ou uso de fórmulas alimentares, suplementos vitamínicos, entre outras ações simples que, no entanto, deverão ser realizadas por toda a vida do doente.

Por fim, um ponto importante a destacar sobre o diagnóstico e tratamento para doença rara hereditária diz respeito aos testes preditivos para sujeitos assintomáticos e os testes pré-natais, e aqui adentramos a problemática da reprodução da família diante de doenças de longa duração potencialmente incapacitantes.

Sendo essas doenças hereditárias, muitas vezes espera-se que os parentes que ainda não apresentam sintomas realizem exames preditivos para saber de sua condição genética, especialmente antes de terem filhos. A prerrogativa é que ao conhecer seus fatores de risco as pessoas possam fazer escolhas em suas vidas tendo por base essa herança e seus efeitos na reprodução da família. No entanto, foi possível observar, tanto nessa pesquisa como em outros estudos ${ }^{28,29,37}$ que, no caso de doenças sem cura ou tratamento, os testes preditivos e os pré-natais nem sempre são percebidos como algo que possa favorecer à saúde das pessoas ou mesmo auxilia-las em suas escolhas reprodutivas. Conhecer sua condição genética não é algo desejado por muitas das pessoas assintomáticas que têm uma doença rara hereditária em suas famílias, especialmente em contextos onde o aborto não é legalizado no caso de malformação, ou nos quais as tecnologias de reprodução assistida ainda são caras e pouco acessíveis, como é o caso do Brasil.

Nas entrevistas com as famílias afetadas pela DMJ o diagnóstico foi apontado como algo essencial para as pessoas que já apresentavam os sintomas da doença. Foi a partir do teste genético que muitos dos meus interlocutores conseguiram suas aposentadorias especiais, cartões de acesso gratuito ao transporte público, descontos para compra de automóveis, entre outros benefícios assegurados à pessoa com deficiência. No entanto, quando se tratava da testagem preditiva para os parentes assintomáticos, o valor do diagnóstico era contestado:

A gente aqui só é contra de fazer teste porque, se procurar e achar, já não vai mexer com o psicológico? Meu irmão não faz [não tem sintomas]. Ele diz que ele não faz, se aparecer sintoma ele vai encarar. E eu concordo com ele, eu também não faço, não. Se tiver que aparecer alguma coisa, vai aparecer.
Se fizesse o exame e tivesse como cortar, se tivesse remédio, aí eu dizia: 'Ah não! Vamos fazer o exame porque tem um remédio pra prevenir!', Mas não tem. Então pra que que a gente vai mexer? (S1).

Eu não quero fazer porque a nossa mente constrói tudo na gente. Então, se eu sou diagnosticada hoje, aos 35 anos, eu acho que eu posso acelerar mentalmente algumas manifestações [...]. Se o médico da minha mãe falar: 'é importante todo mundo fazer porque descobriu um tratamento!' Então vamos todo mundo fazer, eu vou fazer. Agora, eu não fazer só pra saber, só se tivesse um tratamento (S5-mulher, sem sintomas, mãe com diagnóstico para $D M J)$.

A melhor coisa a se fazer nesse aspecto é viver. Eu não recomendo minhas filhas de fazer exame de DNA pra saber se tem porque não vai adiantar, já nasceram, já estão aí, o negócio é viver, aproveitar a vida (S2).

Mais do que analisar as porcentagens e estatísticas, os heredogramas, as consequências físicas a longo prazo, meus interlocutores geralmente avaliavam as possibilidades de vida que se pode ter com essa doença. A probabilidade de herdar ou transmitir o gene para DMJ é de $50 \%$, alto para os padrões biomédicos, relativamente equilibrado para as famílias, que apostam mais no sentido negativo desse número $(50 \%$ de chances de não ter herdado ou de não transmitir). Além disso, a proximidade com pais, tios, tias, primos que desenvolvem a doença, mas que tiveram uma carreira profissional ou ainda trabalham, que podem dirigir mesmo sem equilíbrio quando em pé, que usam computador quando não mais conseguem escrever, que tiveram tempo para criar os filhos antes de adoecer, tudo isso entrava no rol das avaliações sobre a testagem genética preditiva e o desejo de ter ou não filhos.

Neste sentido, a questão da idade de manifestação da doença tinha papel importante no modo como ela era percebida pelos membros das duas famílias. Sua expressão tardia e com limitações gradativas que não impediram totalmente o desempenho de algumas funções, embora tidas como indesejáveis, eram compreendidas como algo tolerável, dentro do processo de envelhecimento. O início da doença quase sempre por volta dos 40 anos era percebido como fato que pode permitir a reprodução da família ou que não seria impeditivo para o sujeito programar sua vida profissional. A DMJ tem graus diversificados de comprometimento físico e não compromete a cognição, ao contrário de outras doenças neurológicas raras e hereditárias. Esses fatores muitas vezes são considerados pelas pessoas para negar a 
testagem preditiva ou recusar a ideia de que não podem ou de que não deveriam ter filhos.

Percebeu-se que, ao menos nessas famílias, a procura por um diagnóstico através de testes genéticos estava sendo balizada por diferentes fatores: entre os que tinham sintomas haveria questões sociorrelacionais que poderiam ser resolvidas com o diagnóstico em mãos, como a necessidade de comprovar perante outros sua condição genética e legitimar seu afastamento do trabalho. Para os que não apresentavam os sintomas, o teste era visto como meio de antecipar o sofrimento e a angustia se desse positivo, e até mesmo acelerar o desenvolvimento da doença, por fazer com que a pessoa ficasse "o resto da vida pensando nisso", e não como meio de programar a vida ou fazer as escolhas reprodutivas.

Nas doenças de herança autossômica recessiva, cujos sintomas aparecem já ao nascimento ou nos primeiros anos de vida, o diagnóstico do filho doente revela para os pais a sua condição de portadores de um gene "defeituoso", que para eles não provoca a doença, mas que representa 25\% de chance de gerarem filhos doentes. Neste caso, são os testes pré-natais que emergem como tecnologia diagnóstica a ser considerada e também aqui observam-se resistências, pois a legislação brasileira não permite interrupção da gestação caso o teste seja positivo para uma doença rara que cause malformação ou sério comprometimento cognitivo. Deste modo, questiona-se muitas vezes a busca pelo diagnóstico precoce no feto, especialmente para os casos sem tratamento medicamentoso ou intervenções capazes de minorar os efeitos da doença ${ }^{27}$. Mesmo em países onde a legislação permite o aborto no caso de doença rara e malformação, há pesquisas que demonstram as tensões morais pelas quais os parentes assintomáticos passam ao se defrontar com essa possibilidade nas suas escolhas reprodutivas ${ }^{29,30}$. Nestes casos, não é apenas a lógica da saúde que é considerada para o uso dos testes, mas também as relações afetivas e relacionais travadas no interior da família com a doença e seus portadores, e as possibilidades de vida com uma condição rara.

Esses dados nos permitem questionar em parte a afirmação de Finkler ${ }^{8,18}$ de que a biogenética estaria formatando relações de parentesco antes baseadas na honra, no compartilhamento de crenças, valores e modos de ser, pela fisicalidade do gene. Observou-se, a partir do contato com essas famílias, e em outros estudos aqui citados, que a genética tem muita importância, mas não se torna um determinante para a construção de projetos relacionados à família e sua reprodu- ção. Valores associados à autonomia individual e profissional, à percepção das idades e suas fases no curso da vida, bem como às relações afetivas travadas entre os parentes com e sem a doença, têm um valor significativo no modo como uma doença rara hereditária é encarada e percebida pelos membros assintomáticos. Isso não significa que as pessoas não compreendem o risco de transmissão da doença aos descendentes, suas limitações e consequências físicas, mas sim que evocam outras formas de significar esses elementos, a fim de tomar decisões e construir projetos, atitude que faz parte da experiência com doenças de longa duração.

Durante o trabalho de campo, ouvi relatos de pessoas que disseram que alguns médicos, não especialistas em genética médica, afirmaram que a única maneira de acabar com a doença hereditária na família seria acabando com a própria família, ou seja, interrompendo o ciclo reprodutivo dos descendentes. O peso dessa afirmação é imenso e difícil de suportar, quando sabemos que a constituição da família através do parentesco consanguíneo é um valor forte em nossa sociedade.

Castiels et al. $^{38}$ afirmam que algumas abordagens da biogenética têm produzido alto grau de responsabilização para pessoas que vêm de contextos familiares marcados pela cronicidade, sobretudo, uma noção de "responsabilidade reprodutiva" que deve ser construída a partir de uma "escolha informada" e uma "atitude geneticamente responsável”. Essa é uma acepção muito corrente em contextos de economia liberal avançada $^{39}$, porém mesmo nesses cenários tal retórica enfrenta resistências, pois as escolhas reprodutivas envolvem relações que dificilmente são equalizadas sem ruídos, sem negociações diversas com valores, afetos e expectativas relacionadas à família.

Por fim, cabe questionarmos em que sentido podemos falar em "responsabilidade reprodutiva" ou "escolha informada", quando sabemos que muitas famílias com doenças raras hereditárias alcançam um diagnóstico definitivo depois de anos, às vezes, décadas de itinerário terapêutico, quando já constituíram sua descendência. Para complicar a ideia de "escolha", que é altamente individualizadora, precisamos também considerar o que pode ser escolhido. No Brasil, tanto os testes genéticos preditivos quanto as técnicas de fertilização in-vitro com seleção de embriões (que permitir a reprodução sem a transmissão de genes causadores de doenças $\operatorname{raras}^{40}$ ) são caros, não estão disponíveis na rede pública de saúde, 
sendo, portanto acessíveis apenas a uma parcela reduzida da população brasileira. Some-se a isso a proibição de interrupção da gestação em casos comprovados de malformação ou anomalias genéticas, devemos nos perguntar: de que possibilidades de escolha estamos falando? Neste sentido, os testes genéticos preditivos e os pré-natais precisam vir acompanhados de uma rede de suporte para os sujeitos e suas famílias, sem a qual tal conhecimento sobre si não poderá resultar em maior cuidado ou atenção à saúde individual e familiar.

\section{Considerações finais}

Sabemos que a família desempenha papel fundamental no modo como a experiência da doença, especialmente as crônico-degenerativas, é vivida e significada pela pessoa doente. A família está presente na construção de discursos e práticas terapêuticas diversas e é alvo de políticas públicas de saúde nacionais, a exemplo da Estratégia Saúde da Família. No entanto, poucas ações têm contemplado de forma mais ampla a experiência de famílias vivendo com doenças raras hereditárias, e os aspectos sociais aqui implicados como: o acesso a tratamentos e assistência em saúde, educação, mobilidade e previdência social e, não menos importante, a continuidade da própria família.

Ter mais profissionais de saúde habilitados para detecção precoce de doenças raras hereditárias na atenção básica possivelmente evitaria os longos anos de espera por um diagnóstico, essa é uma das demandas das associações de pacientes, a inclusão de disciplinas sobre genética médica e doenças raras nos cursos de medicina. Porém, essa ação não resolveria o problema da reprodução da família se as tecnologias disponíveis continuarem com oferta inexistente ou com custos proibitivos, e se não compreendermos adequadamente quais valores norteiam as escolhas reprodutivas. É preciso considerar que, mesmo quando disponíveis, tais tecnologias são usadas e significadas de diversas formas, como já observado em outros estudos. Porém, ao menos nesses casos, é possível falar em alguma possibilidade de escolha, ou de uma recusa em escolher ${ }^{30}$. Assim, uma agenda efetiva para tratar as doenças raras hereditárias precisa considerar os aspectos relacionados à família como um valor social im- portante, os dilemas morais que fazem parte do universo relacional dessas pessoas e a necessidade de se oferecer mais do que apenas uma "educação em genética".

Um outro aspecto a destacar é que o cuidado para com as doenças raras hereditárias parece estar centrado, no debate público, em torno dos medicamentos de alto custo, quando apenas um número reduzido de doenças raras possui algum tratamento medicamentoso ${ }^{41}$. Os processos de judicialização que acompanham esse debate ${ }^{42,43}$ podem ofuscar as necessidades da grande maioria dos doentes raros que precisam de ações bem mais simples e baratas, mas ainda assim pouco acessíveis na rede pública para doenças de longa duração, como fisioterapia, fonoaudiologia, terapia ocupacional ou fórmulas alimentares.

Por fim, porém não menos importante, está o silenciamento em torno dos cuidadores. Infelizmente, dado o limite desse artigo e seus objetivos, não será possível discutir em profundidade essa questão, mas é preciso pontuar que em sua grande maioria são as mulheres - mães, esposas, irmãs ou filhas - as responsáveis pelo cuidado do doente raro, assim como pela atuação na esfera pública, demonstrando a correlação desse campo com outros estudos sobre o cuidado de doentes crônicos que atestam o mesmo ${ }^{34-36,44,45}$. Um número considerável de associações de paciente é coordenado por pais e, principalmente, mães de crianças com doenças raras hereditárias ${ }^{46}$. Gênero é, assim, uma dimensão importante na esfera do cuidado e de quais membros da família se tornam cuidadores, e relevante no que diz respeito à reprodução, considerando o valor simbólico dado à maternidade. Neste sentido, sobre as mulheres tem recaído uma grande carga moral, econômica e emocional relacionada ao cuidado do paciente com doença rara hereditária. As necessidades desse contingente de cuidadoras, que são também agentes políticos, precisam ser melhor observadas e discutidas nas políticas públicas e em futuras pesquisas sobre o tema.

Diante do exposto, é preciso observar que uma doença rara hereditária envolve moralidades, desejos e afetos que serão considerados na significação dos diagnósticos e dos tratamentos, e no uso (ou não uso) das tecnologias médicas de forma bastante variada, pois antes de ser uma condição clínica, essas doenças são uma questão de família, e como tal não escapam a sua complexidade. 


\section{Agradecimentos}

Ao Conselho Nacional de Desenvolvimento Científico e Tecnológico (CNPq) pela bolsa de pós-doutorado que possibilitou a realização de parte desta pesquisa.

\section{Referências}

1. Brasil. Portaria No 199, de 30 de Janeiro de 2014. Institui a Política Nacional de Atenção Integral às Pessoas com Doenças Raras, aprova as Diretrizes para Atenção Integral às Pessoas com Doenças Raras no âmbito do Sistema Único de Saúde (SUS) e institui incentivos financeiros de custeio. Diário Oficial da União 2014; 31 jan.

2. Barbosa L, Monsores N. Linhas de cuidado e itinerários terapêuticos para doenças raras no Distrito Federal. Tempus Actas de Saúde Colet 2016; 10(3):69-80.

3. Luz GS, Silva MRS, DeMontigny F. Doenças raras: itinerário diagnóstico e terapêutico das famílias de pessoas afetadas. Acta Paul Enferm 2015; 28(5):395-400.

4. Monsores N. Questões bioéticas sobre doenças genéticas raras. Câmara dos Deputados. 54 a Legislatura - 3a Sessão Legislativa. Série Separatas de Discursos, Pareceres e Projetos, no 21/2013.

5. Saute J, Jardim L. Machado Joseph disease: clinical and genetic aspects, and current treatment. Expert Opinion on Orphan Drugs 2015; 3(5):517-535.

6. Aureliano WA. Health and the Value of Inheritance: The meanings surrounding a rare genetic disease. $\mathrm{Vi}$ brant 2015; 12:109-140.

7. Strathern M. Reproducing the Future: Essays on Anthropology, Kinship and the New Reproductive Technologies. Manchester: Manchester University Press; 1992.

8. Finkler K. Experiencing the new genetics: family and kinship on the medical frontier. Pittsburgh: University of Pennsylvania Press; 2000.

9. Luna N. Provetas e Clones: uma antropologia das novas tecnologias reprodutivas. Rio de Janeiro: Editora Fiocruz; 2007.

10. Herzlich C, Pierret J. Illness and self in society. Baltimore and London: The Johns Hopkins University Press; 1987.

11. Kleinman A. The Illness Narratives: suffering, healing and the human condition. New York: Basic Books, Inc.; 1988.

12. Mattingly C. Narrative and cultural construction of illness and healing. Berkeley, Los Angeles: University of California Press; 2000.

13. Maksud I. Doenças/Adoecimentos/Sofrimentos de Longa Duração: diálogos da Ciências Sociais com a Saúde Coletiva. Política \& Trabalho Revista de Ciências Sociais 2015; 42:197-209.

14. Schneider D. American Kinship: A Cultural Account. Chicago: University of Chicago Press; 1980.

15. Fonseca C. Família e Parentesco na Antropologia Brasileira Contemporânea. In: Duarte LFD, organizador. Horizontes das Ciências Sociais no Brasil: Antropologia. São Paulo: ANPOCS; 2010. p. 123-154.

16. Strathern M. Necessidade de pais, necessidade de mães. Revista Estudos Feministas 1995; 3(2):303-329.

17. Fonseca C. Parentesco, Tecnologia e Lei na Era do DNA. Rio de Janeiro: EdUERJ; 2014.

18. Finkler K. The Kin in the Gene: The Medicalization of Family and Kinship in American Society. Current Anthropology 2001; 42(2):235-249. 
19. Rabinow P. Antropologia da Razão. Rio de Janeiro: Relumé Dumara; 1999.

20. Lock M. Breast cancer: reading the omens. Anthropology Today $1998 ; 14(4): 7-16$.

21. Gibbon S. Family medicine, 'la herencia' and breast cancer: understanding the (dis)continuities of predictive genetics in Cuba. Soc Sci Med 2011; 72(11):17841792.

22. Paiva e Silva RB, Ramalho AS. Riscos e benefícios da triagem genética: o traço falciforme como modelo de estudo em uma população brasileira. Cad Saude Publica 1997; 13(2):285-294.

23. Guedes C, Diniz D. Um caso de discriminação genética: o traço falciforme no Brasil. Physis 2007; 17(3):501520 .

24. Diniz D, Guedes C. Confidencialidade, aconselhamento genético e saúde pública: um estudo de caso sobre o traço falciforme. Cad Saude Publica 2005; 21(3):747755.

25. Guedes C, Diniz D. A Ética na História do Aconselhamento Genético: um desafio à educação médica. Rev Brasileira de Educação Médica 2009; 33(2):247-252.

26. Novoa MC, Fróes Burnham T. Desafios para a universalização da genética clínica: o caso brasileiro. $\mathrm{Rev} \mathrm{Pa}$ nam Salud Publica 2011; 29(1):61-68.

27. Corrêa MCDV, Guilam MCR. O discurso do risco e o aconselhamento genético pré-natal. Cad Saude Publica 2006; 22(10):2141-2149.

28. Chilobeck G, Lock M, Sehde M. Postgenomics, uncertain futures, and the familiarization of susceptibility genes. Soc Sci Med 2011; 72(11):1768-1775.

29. Boardman FK. The expressivist objection to prenatal testing: The experiences of families living with genetic disease. Soc Sci Med 2014; 107:18-25.

30. Kelly SE. Choosing not to choose: reproductive responses of parents of children with genetic conditions or impairments. Sociology of Health \& Illness 2009; 31(1):81-97.

31. Rabeharisoa V, Callon M, Filipe AM, Nunes JA, Paterson P, Vergnaud F. From 'politics of numbers' to 'politics of singularisation': Patients' activism and engagement in research on rare diseases in France and Portugal. Biosocieties 2014; 9(2):194-217.

32. Soares JL, Araújo LFS, Bellato R. Cuidar na situação de adoecimento raro: vivência da família e sua busca por amparo dos serviços de saúde. Saúde Soc. 2016 25(4):1017-1030.

33. Portugal S, Alves JP. Doenças raras e cuidado: um olhar a partir das redes sociais. In: Congresso Ibero-Americano de Doenças Raras. Actas. Coimbra: Universidade de Coimbra; 2015. p. 34-40.

34. Karsch UMS, organizador. Envelhecimento com dependência: revelando cuidadores. São Paulo: EDUC; 1998.

35. Pinto JMS, Nations MK. Cuidado e doença crônica: visão do cuidador familiar no Nordeste brasileiro. Cien Saude Colet 2012; 17(2):521-530.
36. Silva LMS, Tavares JSC. A família como rede de apoio às pessoas que vivem com HIV/Aids: uma revisão na literatura brasileira. Cien Saude Colet 2015; 20(4):11091118.

37. Konrad M. Predictive genetic testing and the making of the pre-symptomatic person: prognostic moralities amongst Huntington's-affected families. Anthropology and Medicine 2013; 10(1):23-49.

38. Castiel L, Guilam MCR, Vasconcellos-Silva PR, Sanz-Valero J. Os riscos genômicos e a responsabilidade pessoal em saúde. Rev. Panam. Salud Publica/Pan Am J Public Health 2006, 19(3):189-197.

39. Rose N. A politica da própria vida: biomedicina, poder e subjetividade no século XXI. São Paulo: Paulus; 2013.

40. Franklin S, Roberts C. Born and Made: an ethnography of preimplantation genetic diagnosis. Princeton: Princeton University Press; 2006.

41. Barbosa RL. Pele de Cordeiro: associativismo e mercado na produção de cuidado para as doenças raras. Lisboa: Chiado Editora; 2015.

42. Biehl J. The Judicialization of Biopolitics: Claming the right to pharmaceuticals in Brazilian courts. American Ethnologist 2013; 40(3):419-436.

43. Diniz D, Medeiros M, Schwartz IVD. Consequências da judicialização das políticas de saúde: custos de medicamentos para as mucopolissacaridoses. Cad Saude Publica 2012; 28(3):479-489.

44. Knauth D. Morte Masculina: homens portadores do vírus da Aids sob a perspectiva feminina. In: Duarte LFD, Leal OF organizadores. Doença, Sofrimento, Perturbação: perspectivas etnográficas. Rio de Janeiro: Fiocruz; 1998. p. 183-198.

45. Lemos ND, Gazzola JM, Ramos LR. Cuidado do paciente com Alzheimer: o impacto da doença no cuidador. Saúde Soc. 2006; 15(3):170-179.

46. Barbosa RL. Para uma nova perspectiva sobre o campo das doenças raras: a motivação das associações civis em debate. Tempus Actas de Saúde Colet 2015; 9(2):57-74.

Artigo apresentado em 13/06/2017

Aprovado em 25/09/2017

Versão final apresentada em 27/09/2017 
